\title{
Significados da doença, morte e perdão em mulheres com Cancro da mama'
}

Fátima Andrade²

Carla Fonte ${ }^{3}$

doi:/10.11144/Javeriana.ie19-1.sdmp

Cómo citar: Andrade F, Fonte C. Significados da doença, morte e perdão em mulheres com Cancro da mama. Investig Enferm. Imagen Desarr. 2017;19(1): 65-80. http://dx.doi. org/10.11144/Javeriana.ie19-1.sdmp

1. Artículo original de investigación. Fecha de recepción: 23 de Junio 2015. Fecha de aceptación: 14 de Enero de 2016

2. Licenciada e Mestre em Psicologia. Universidade Fernando Pessoa Faculdade de Ciências Humanas e Sociais. Porto, Portugal. Correio eletrônico: fatima.andrade.psi@gmail.com

3. PHD. Professora Auxiliar Universidade Fernando Pessoa Faculdade de Ciências Humanas e Sociais. Porto, Portugal. Correio eletrônico: cfonte@ufp.edu.pt 


\section{Resumo}

Objetivo: Perceber os significados sobre a doença, morte e perdão em mulheres com cancro da mama e ainda quais as conceções relativamente ao futuro após um diagnóstico de cancro. Metodologia: foi utilizada uma abordagem qualitativa, através da realização de entrevistas semiestruturadas a um grupo de oito mulheres com diagnóstico de cancro da mama. As histórias pessoais foram depois analisadas utilizando a Grounded Analysis para obter uma compreensão holística e aprofundada do significado que os indivíduos atribuem à sua experiência vivencial. Resultados: Os dados encontrados indicam que um diagnóstico de cancro da mama tem um impacto associado a sentimentos de medo, incapacidade, dependência e morte. Para enfrentar o cancro, a mulher procura construir um novo significado sobre conceitos como o perdão, doença, sonhos para o futuro, tentando encontrar uma redefinição dos papéis que lhe são atribuídos e procurando ter um novo olhar sobre o significado da vida. Conclusões: Os resultados dão indicadores relevantes aos profissionais de saúde, quer de compreensão nas mudanças e reformulação de significados que ocorrem no doente oncológico, quer ao nível pessoal provocados pela doença e seus tratamentos, quer ao nivel familiar e social, e intervenção no alívio do confronto com o sofrimento e a morte.

Palauras-chave: Perdão, neoplasias, morte, doença

\section{Significados sobre la enfermedad, la muerte y el perdón en mujeres con cáncer de mama}

\section{Resumen}

Objetivo: Comprender el significado de la enfermedad, la muerte y el perdón en las mujeres con cáncer de mama y las concepciones sobre el futuro después de un diagnóstico de cáncer. Metodo: se desarrolló un enfoque cualitativo, mediante la realización de entrevistas semi-estructuradas con un grupo de ocho mujeres con diagnóstico de cáncer de mama. Las historias personales fueron analizadas utilizando Grounded Análisis para una comprensión integral y en profundidad del significado que los individuos atribuyen a su experiencia de vida. Resultados: indican que un diagnóstico de cáncer de mama tiene un impacto asociado con sentimientos de miedo, fracaso, dependencia y muerte. Para enfrentar el cáncer, la mujer busca construir un nuevo significado en conceptos tales como el perdón, la enfermedad, los sueños para el futuro, tratando de encontrar una redefinición de los roles asignados a él y que busca tener una nueva mirada sobre el sentido de la vida. Conclusiones: los resultados proporcionan indicadores importantes para los profesionales de salud, para entender los cambios y la alteración de significados que se producen en pacientes con cáncer, ya sea a nivel personal causada por la enfermedad y sus tratamientos, o a nivel familiar y social, e intervenir en la confrontación con el alivio del sufrimiento y la muerte.

Palabras clave: Perdón; neoplasia; muerte; enfermedad 


\section{Meanings about the disease, death and forgiveness in women with breast cancer}

\section{Abstract}

Objective: To understand the meaning of illness, death and forgiveness in women with breast cancer and conceptions about the future after a cancer diagnosis. Method: A qualitative approach was developed using semi- structured interviews with a group of eight women diagnosed with breast cancer. Personal histories were analyzed using Grounded Analysis for a comprehensive and in-depth understanding of the meaning that individuals attribute to their life experience. Results: They indicate that a diagnosis of breast cancer has an impact associated with feelings of fear, failure, dependency and death. To cope with cancer, the woman seeks to build a new meaning in concepts such as forgiveness, illness, dreams for the future, trying to find a redefinition of the roles assigned to cancer and looking to have a new look on the meaning of life. Conclusions: The results provide important indicators for health professionals to understand the changes and altered meanings that occur in cancer patients, either on a personal level caused by the disease and its treatment, or family and social level, and intervene in the confrontation with the relief of suffering and death.

Keywords: Forgiveness; neoplasia; death; disease 


\section{Introdução}

Ao adoecer, as preocupações das pessoas ficam centradas na sua vida e nas implicações decorrentes da doença (1). Sendo uma experiência única e subjetiva (2), o cancro é um grave problema de saúde pública (3), frequentemente associado a elevados índices de mortalidade, fraca qualidade de vida e uma conceptualização negativa do sentido de vida (4). A literatura retrata que as respostas do ponto de vista psicológico a um diagnóstico de cancro e aos seus tratamentos associados depende de um grande número de fatores (5). Alguns destes fatores são o nivel avançado ou não da doença; as opções de tratamento e seus efeitos secundários; a idade a quando do diagnóstico (6), a saúde em geral da pessoa, as crenças espirituais (7) a presença ou não de suporte social (8) e ainda o estilo pessoal de coping (9). De fato, um diagnóstico de cancro tem subjacente uma ideia de doença que conduz fatalmente à morte. Este estigma de doença fatal prevalece através dos tempos, mesmo depois de todos os progressos feitos pela medicina nas últimas décadas. A investigação mostra que, no caso das mulheres com cancro da mama, as estratégias de coping por elas utilizadas para lidar com a doença são importantes preditores de maior ou pior adaptação à mesma. Por exemplo, as mulheres que se culpam a si próprias pela doença, reportam niveis maiores de perturbação e piores indicadores de qualidade de vida, do que aquelas que optam pelo perdão e são também mais espirituais $(5 ; 10)$. Estudos têm mostrado evidência de que o perdão, enquanto estratégia de coping, permite a redução de pensamentos e sentimentos negativos, e também o desenvolvimento de compaixão e repostas comportamentais positivas, que permitem a redução da ansiedade e depressão (10). De fato, apesar de os benefícios do perdão ao nível da saúde ainda estarem pouco investigados, um estudo de Romero, et al. (11) com mulheres com cancro da mama, verificou que uma atitude de auto-perdão estava associada a um maior ajustamento psicológico ao cancro, devido a uma diminuição da culpabilização de si próprias por terem desenvolvido cancro, o que afetou positivamente o seu humor e qualidade de vida.

Atendendo ao exposto pareceu-nos importante desenvolver um estudo sobre os significados da doença, morte e perdão em mulheres com cancro da mama, procurando ainda compreender em que medida o perdão surge na vida destas pessoas como relevante do seu coping com a doença e a morte.

\section{Método}

A escolha da metodologia de investigação foi feita tendo em atenção a natureza da problemática que queríamos estudar. Na perspetiva de Strauss e Corbin (12), os métodos qualitativos podem ser utilizados para o estudo de áreas pouco conhecidas, e para obter detalhes acerca da vivência de fenómenos como sentimentos, processos de pensamento e emoções, que dificilmente seriam obtidos através de métodos quantitativos. Nesta investigação optamos pela "Grounded Analysis que é uma metodologia alicerçada na "Grounded Theory" - abordagem de investigação qualitativa utilizada para explorar os processos sociais nas interações humanas, e o significado associado ao fenómeno vivido pelos participantes (13). O importante neste modelo 
de investigação são os significados que cada ser humano atribui aos acontecimentos da sua vida e pelo facto de através destes, podermos ter acesso à realidade construída socialmente através da relação que se estabelece entre o investigador e o objeto de estudo (14). Perante um diagnóstico de cancro é frequente haver uma resinificação do sentido da vida e também da morte, e nesse sentido, a questão de investigação da qual partimos é a seguinte: Qual será a perceção da morte em doentes oncológicos, e que aspetos da sua vida poderão contribuir para a emergência do perdão?

Os objetivos específicos pretendiam: 1) Identificar os conteúdos do discurso sobre a doença produzidos pelos doentes oncológicos e analisar de que forma este discurso se articula com a perceção de morte; 2) Analisar as conceções e significados do perdão em doentes oncológicos; 3) Identificar os conteúdos do discurso em doentes oncológicos relativamente ao futuro.

A amostra foi não probabilística e intencional. Fizeram parte desta investigação, 8 mulheres com doença oncológica (cancro da mama) detetada nos últimos cinco anos, com idades compreendidas entre os 30 e os 60 anos, de uma Associação de Apoio a Doentes com Cancro na zona norte de Portugal. O número final de participantes (oito) seguiu as orientações desta metodologia relativamente ao número de sujeitos a incluir nos estudos (14), e ainda devido às condições de inclusão selecionadas pelos investigadores. Estas condições foram: estarem ainda a ser submetidos a algum tipo de tratamento relacionado com a doença, não terem comprometimento crítico das funções vitais, terem boa orientação temporal e espacial e com capacidade de dar respostas às questões que faziam parte da entrevista semiestruturada criada para o efeito. A recolha de dados ocorreu no mês de Julho de 2014, após cumpridos os procedimentos relativos aos princípios éticos considerando a "Declaração de Helsínquia" da Associação Médica Mundial (Helsínquia 1964; Tóquio 1975; Veneza 1983; Hong Kong 1989; Somerset West 1996 e Edimburgo 2000), que passaram pela autorização da comissão de ética Universidade Fernando Pessoa, no Porto, Portugal e da referida associação, bem com pelo Consentimento Informado das utentes que aceitaram participar na pesquisa. Garantimos o anonimato dos sujeitos que participaram no estudo através da criação de um código simples associado a cada uma, com um número de 1 a 8 de forma aleatória na sequência da realização das entrevistas. Neste estudo utilizou-se como instrumento para coleta de dados a entrevista semiestruturada composta especificamente por pontos e tópicos previamente estabelecidos de acordo com a problemática central da investigação. As entrevistas foram registadas em áudio, identificado pelo número da participante tendo-se depois efetuado a transcrição das entrevistas. Após esta transcrição das entrevistas e terminada a análise das mesmas o registo áudio foi eliminado para garantir o anonimato das participantes. As entrevistas foram realizadas face a face por uma das investigadoras deste trabalho, que tem formação em psicologia, numa sala individualizada na referida instituição. O guião da entrevista incluiu os temas de interesse para o investigador, relacionados com o fenómeno em estudo, constituído com as seguintes questões: 1 - O que pensa sobre o perdão? 2 - Acha que o perdão pode ser importante para resolver conflitos, quando há um diagnóstico 
de cancro?; 3- Como poderá o perdão ser facilitador de bem-estar perante um diagnóstico de cancro?; 4- O que significa para si saber que há pessoas doentes?; 5- Quais as doenças que mais a assustam?; 6- Como foi para si ter um diagnóstico de cancro?; 7- O que considera que mudou na sua vida após o diagnóstico de cancro?; 8- Quais os seus sonhos?; 9- Que projetos tem para o futuro?; 10- Acha que devemos pensar na morte?; 11- Como imagina a sua vida daqui a cinco anos?; 12- Acredita que pode realizar os seus sonhos?; 13- Já teve contacto com a morte?; 14- Como é para si lidar com a morte de alguém?; 15- Que pessoas ou situações mais contribuíram para o ajudar a lidar com a ideia de morte?; 16- O que pensa ser importante para ajudar a lidar com o medo?; 17- Como é para si pensar na sua própria morte?

\section{Apresentação e Discussão dos Resultados}

Após a transcrição na íntegra das entrevistas, desenvolveu-se a análise para codificação das mesmas, partindo das unidades de significados encontrados nos discursos e construindo categorias a partir dos dados recolhidos, de acordo com os princípios de análise de dados propostos na Grounded Analysis (14). Estas categorias vão evoluindo de forma a serem cada vez mais definidas e elaboradas ao longo do trabalho, sendo as primeiras categorias a surgir o mais próximo possivel da linguagem utilizada pelas participantes. A finalidade principal desta categorização tem a ver com o integrar o que é particular no geral tendo em conta os dados brutos e as categorias mais genéricas, num movimento contínuo de andar de trás para a frente. O procedimento de categorização inicia-se pela seleção do material relevante para a análise. Após a seleção passa-se a uma categorização descritiva que consiste em fazer uma categorização com base na terminologia usada pelos entrevistados, sendo a unidade de análise a frase/ideia expressa por eles (12).

\section{Resultados obtidos na categorização descritiva}

Esta categorização é feita através da elaboração de memoings do investigador, registando assim as ideias gerais e ainda iniciais das primeiras leituras das entrevistas, permitindo o levantamento de ideias gerais acerca dos significados dos participantes, ainda próximas do discurso dos mesmos. Assim ao longo desta categorização foram emergindo ideias e hipóteses de significados comuns, permitindo posteriormente a construção de categorias de $1^{\mathrm{a}}$ e $2^{a}$ ordem, e categorias centrais e a hierarquização das categorias que se apresentam em seguida (14).

\section{Resultados obtidos na categorização conceptual, na categorização central e na hierarquização das categorias}

Das respostas obtidas das utentes relativamente às três primeiras perguntas 
sendo o perdão um facilitador de bem-estar perante o diagnóstico de cancro e ainda a importância do perdão em si próprio e nos outros (cf. Tabela 1).

TABela 1. Categoria central e categorias de $1^{\mathrm{a}}$ e $2^{\mathrm{a}}$ ordem relativamente ao tema perdão

\begin{tabular}{|c|l|l|}
\hline \multirow{2}{*}{ Categoria Central } & \multicolumn{1}{|c|}{ Categoria de $\mathbf{1}^{\mathbf{a}}$ Ordem } & \multicolumn{1}{|c|}{ Categoria de 2a Ordem } \\
\hline \multirow{3}{*}{ Importância do perdão } & Na relação consigo próprio & $\begin{array}{l}\text { Bem-estar para o próprio } \\
\text { Paz } \\
\text { Lidar com a doença }\end{array}$ \\
\cline { 2 - 3 } & Na relação com os outros & $\begin{array}{l}\text { Bem-estar com os outros } \\
\text { Resolver conflitos }\end{array}$ \\
\hline
\end{tabular}

FOnTE: Elaboração própria

De realçar que 3 das entrevistadas $(n=8)$ considera que o perdão é importante e fundamental, uma vez que perdoar é "estar de bem connosco", "devemos perdoar, é um bem para nós e para os outros também, “o perdão acima de tudo, pudemos estar de muito bem connosco". Por outro lado, 2 ( $n=8)$ consideram que o "perdão é importante porque se nos perdoarem temos paz", "é fundamental, se perdoarmos estamos mais em paz". É notória a importância do perdão para a maioria das entrevistadas e de como perdoar está associado a bem-estar tanto consigo como com os outros e também a paz interior. Verificamos isso em 2 utentes $(n=8)$ que referem o saber perdoar aliado a algo transcendente, "automaticamente conseguimos ver uma luzinha diferente e conseguimos ascender" "é um dos atos mais difíceis, temos que perdoar dentro do nosso coração, as coisas mais difíceis são as mais lindas, surgem lágrimas pelo caminho, surgem coisas maravilhosas". Esta capacidade de perdoar como algo transcendente que provoca bem-estar apesar da dificuldade, poderá funcionar como uma estratégia de coping, referida diversas vezes na literatura, servindo para ajudar a ultrapassar a mágoa e ressentimento, permitindo uma melhoria do funcionamento psicológico. Diversos trabalhos têm sublinhado a importância do perdão na redução de sentimentos negativos, diminuindo a ansiedade e depressão e ainda promovendo o bem-estar psicológico em geral $(11,15)$. A maioria das entrevistadas, $6(n=8)$ considera muito importante o perdão para resolver conflitos quando há um diagnóstico de cancro, apesar de muitas referirem que o perdão é importante em todos os momentos, mesmo quando não há doença. Ficou também evidente como é importante o perdão perante um diagnóstico de cancro, pois é sinónimo de bem-estar, ajuda a melhorar, traz tranquilidade e paz. Isto vem de encontro aos estudos que demonstram que as intervenções para o perdão, seriam adequadas se integradas em cuidados paliativos, na medida em que aumentam a saúde psicológica no final da vida (16). A maioria, $7(n=8)$ considera que é importante e traz bem-estar, "tem toda a importância, acho que é o bem-estar da pessoa", "devemos perdoar, mesmo sem ser com cancro", "eu creio que é bom, embora não tenha pensado nisso, se pensar, dá um pouco mais de paz a quem está doente", "ajuda a gente a ficar mais tranquila", "se perdoo estou mais tranquila, fico bem comigo". Há ainda 1 das entrevistadas $(n=8)$ 
que considera que a doença lhe abriu os olhos: "Nunca, senti que tivesse de perdoar, eu agradeço. A doença abriu-me os olhos. Andei a dormir. Eu não via, dormia." Esta dimensão positiva associada ao perdão que encontramos na maioria das entrevistadas mostram como o perdão está associado a felicidade e bem-estar, indo de encontro aos estudos que demonstram que a escrita de cartas de perdão, aumenta a felicidade de forma significativa, originando afetos mais positivos e sentimentos de paz (17).

Das respostas obtidas das utentes, relativamente às questões $n^{\circ} 4,5$, 6, 7 e 16, que envolvem questões relacionadas com a doença surgiu uma categoria central "perceção da doença em si próprio e nos outros" (cf. Tabela 2).

TABela 2. Categoria central e categorias de $1^{\mathrm{a}}$ e $2^{\mathrm{a}}$ ordem relativamente ao tema perceção da doença

\begin{tabular}{|c|c|c|}
\hline Categoria Central & Categoria de $1^{\text {a }}$ Ordem & Categoria de $2^{\text {a }}$ Ordem \\
\hline \multirow[t]{2}{*}{$\begin{array}{l}\text { Perceção da doença em si } \\
\text { próprio }\end{array}$} & Aspetos negativos & $\begin{array}{l}\text { Medo } \\
\text { Morte } \\
\text { Cancro } \\
\text { Sofrimento } \\
\text { Tristeza } \\
\text { Mal-estar } \\
\text { Incapacidade } \\
\text { Degeneração }\end{array}$ \\
\hline & Aspetos positivos & $\begin{array}{l}\text { Aprendizagem } \\
\text { Perdão } \\
\text { Espiritualidade } \\
\text { Acordar para a vida } \\
\text { Aceitação } \\
\text { Otimismo } \\
\text { Valorizar a vida }\end{array}$ \\
\hline \multirow[b]{2}{*}{$\begin{array}{l}\text { Perceção da doença nos } \\
\text { outros }\end{array}$} & Aspetos negativos & Dificuldades relacionais \\
\hline & Aspetos positivos & $\begin{array}{l}\text { Valorizar a vida } \\
\text { Otimismo } \\
\text { Perdão }\end{array}$ \\
\hline
\end{tabular}

FONTE: elaboração própria

A perceção da doença, seja em si próprio seja nos outros, está de uma maneira geral associada a mal-estar, tristeza e sofrimento. Parece evidente que abordar algo relacionado com o tema doença, remete muitas das entrevistadas para a sua própria narrativa pessoal, pelo próprio efeito devastador da doença oncológica. A maioria das utentes, $(n=6)$ considera que é triste falar disso, que isso lhe traz sofrimento e mal-estar e que ninguém merecia estar doente, principalmente as crianças: “Tristeza, muita tristeza. Penso muito, principalmente nas crianças", "tristeza, porque me traz muito sofrimento", "tenho pena, toca-me e dói-me muito", "ninguém merecia estar doente, principalmente as crianças", "evito falar disso, a gente sente sempre na pele o mal-estar". Duas das utentes $(n=2)$ referem que apesar de ser mau e de tentar ajudar as pessoas a doença pode ser uma forma de "valorizar a vida" e que é preciso ser "otimista", "é mau, mas a doença pode trazer o outro lado, as pessoas têm que dar valor às coisas boas", "tento ajudar e pensar que 
melhores dias virão”. Face à doença quer seja em si próprio quer nos outros, há sempre sentimentos de tristeza, sofrimento e mal-estar, que envolve mecanismos de adaptação além do confronto com a incerteza acerca do futuro, incerteza acerca do curso da doença. A ideia da sua própria morte torna-se tangivel e quaisquer sintomas físicos podem ser interpretados como um possível agravamento clínico. Quando as pessoas são confrontadas com alguma adversidade, lidam melhor com ela se conseguem uma explicação aceitável para a mesma, o que nem sempre acontece numa doença oncológica (5).

Diversos estudos realizados com doentes com cancro associam doença a sofrimento, verificando-se níveis elevados de sofrimento nas dimensões de sofrimento físico devido à fadiga, à dor, e aos efeitos secundários da quimioterapia, mas também o sofrimento psicológico relacionado com a depressão, pelas consequências e mudanças resultantes da doença e pela crença de possibilidade de morte iminente, havendo uma inter-relação entre várias dimensões $(18,19)$. Por outro lado, verificamos também que a perceção sobre a doença em si próprio e nos outros, não tem apenas aspetos negativos, ligados a medo da morte, tristeza, mal-estar, incapacidade, degeneração. Aspetos positivos como por exemplo o desenvolvimento de uma aprendizagem, um despertar para a espiritualidade, a valorização da vida e reflexão sobre o perdão (11). Nesse sentido haveria uma dimensão positiva na doença e no sofrimento que corresponde a uma dimensão de esperança e otimismo, dando enfase ao poder criativo do sofrimento, pela possibilidade oferecida de crescimento. A doença coloca em causa a mortalidade exigindo a reestruturação interna e externa da pessoa, com a procura de novos significados face à vida e à morte $(20,7)$. O estigma do cancro com tudo o que lhe está associado foi também identificado nos nossos dados, onde se constatou que o maior receio nestas mulheres é mesmo o de deixarem de ter uma vida ativa para passarem a ser dependentes de outros: "Ficar sem puder andar", "é a gente querer fazer as coisas e não puder", "uma doença que me deixe inutilizada", "doenças que provocam degeneração que nos deixa sem qualidade de vida" " doenças degenerativas em que se sofre até morrer”. Duas utentes $(n=2)$ referem o cancro como a doença que mais as assusta: "Assusta-me o cancro", "o cancro vem logo a cabeça rapada". Apenas uma utente, refere que não é o cancro, apesar de dar uma resposta não conclusiva: "O cancro já não me assusta. Há doenças bem piores que o cancro". Quando surge um cancro na mama, o comportamento social das mulheres é afetado, provocando restrições na vida social e disfunção nos diversos papéis que desempenham. Se a mulher é forçada a abdicar do seu trabalho a restringir as atividades domésticas e socias, e a depender de outros, isso pode levar a um maior isolamento social com todas as implicações subjacentes (21).

O cancro como toda a doença, altera e redimensiona a vida social do doente, afetando as suas relações e modificando as suas ações, afetando determinados papéis femininos instituídos, cultural e historicamente $(22,8)$. Os elevados índices de mortalidade, bem como a agressividade das terapêuticas cirúrgicas e farmacológicas, contribuem ainda hoje para uma visão assustadora do cancro (23). Ter um diagnóstico de cancro é uma experiência que ninguém gostaria de passar, pois o cancro continua a ser visto como um 
assunto tabu, associado à morte, tratamentos violentos e intrusivos e uma necessidade constante de acompanhamento hospitalar e cuidados de saúde, capaz de gerar no indivíduo uma multiplicidade de reações psicológicas $(24$, 25). A maioria das utentes $(n=5)$ teve medo, considera que foi mau, assustador, muito difícil, foi ficar sem chão. "Não foi nada bom, sabia que tinha de ser internada mas tinha um filho de 13 anos, tive uma semana para me preparar", "assustador, muito", "muito difícil, um dos palavrões mais terriveis. Daqui a dois meses vou partir", "foi terrivel foi ficar sem chão", "foi mau, muito mau. Perdi a fala, perdi o andar, paralisou-me as cordas vocais". Para outras pessoas esta experiência pode gerar emoções positivas que podem predispor a sentir que a vida tem significado e aumentar a sensibilidade para o significado dessa situação (26). Duas das utentes $(n=2)$ vêm nisto um aprendizado e uma ligação com algo superior: "Conformei-me. Agradeci a Deus por me ter dado um cancro tão leve e pedi-lhe força", "não foi mau, procurei saber mais, sem revolta, sem queixa, adorar e abençoar tudo". Após um diagnóstico de cancro há emoções complexas e alterações no estilo de vida que podem ser devastadoras não apenas para o próprio mas também para os membros da família da pessoa com cancro. As relações conjugais podem sair reforçadas ou deterioradas. A diminuição da auto-estima, na mulher mastectomizada, repercute-se na auto-imagem, afectando a sexualidade e, por consequência a relação com o companheiro (27). A vida muda por completo após um diagnóstico de cancro. Isso ficou evidente na grande maioria das respostas dadas. A maioria das utentes $(n=7)$ considera que houve uma mudança total nas suas vidas e todas as respostas tem subjacente um aprendizado que a doença lhes trouxe mudando a percepção sobre si próprias e a realidade à sua volta. "Mudou as rotinas, mudou a maneira de ver o mundo em geral. O saber ouvir as pessoas, saber perdoar, não ligar às discussões", "mudou muita coisa, tive de parar. Não parava, tive de parar", "mudou tudo, nunca estava nada bem para mim. Era muito ciumenta", "A minha qualidade de vida. Era muito ativa. Agora aprendi a viver de outra maneira", "mudou tudo, tudo. O simples facto de puder olhar para uma simples flor a cair de uma árvore, um passarinho" "mudou muita coisa, muita coisa. Fui descobrir dons e qualidades em mim que não tinha desenvolvido, porque não tinha tempo". Os depoimentos de muitas das participantes evidenciaram as dificuldades bem como os medos que surgiram perante uma doença como é o cancro. A procura de novos significados para a vida e a perceção de si próprias, bem como a necessidade de reorganização social, através da mudança de muitos dos papéis desempenhados até então. A incerteza em relação ao futuro, o sofrimento e dor física, a dependência, a perda de controlo sobre os acontecimentos, os efeitos secundários dos tratamentos, a recorrência da doença e os problemas da separação e da morte, são alguns dos aspetos com maior impacto psicológico $(28,29)$. Também as famílias são profundamente afetadas, uma vez que as atividades do quotidiano, os papéis, as relações com os outros e o significado da vida ficam alterados, dado que a vida muda de um estado de saúde para um de doença (30). Nos nossos dados foi ainda possivel verificar que três das utentes $(n=3)$ fazem referência à necessidade de enfrentar o medo/doença, aceitando-o: "Lidarmos bem com 
as coisas, porque amanhã partimos", "enfrentá-lo", "saber que aquilo e um medo é uma coisa que eu penso, eu tenho que ultrapassar, enfrentar". Duas utentes $(n=2)$ apresentam o recurso à espiritualidade como forma de lidar com o medo/doença e o enfrentar. "Procurar a companhia de Deus, pedir a Deus que dê força, paz e luz", "acreditar e termos fé". Apenas uma utente refere "não pensar, acho que a gente tem que se distrair e não pensar" e outra considera a "auto-estima, confiança na própria pessoa " como importante para lidar com o medo/doença.

Das respostas obtidas em relação às perguntas, 8, 9, 10, 11, 12, 13, 14, 15 e 17, emergiu uma categoria central "Futuro" que engloba os sonhos, projetos, o pensar na morte e outros aspetos relacionados com o morrer (cf. Tabela 3).

TABela 3. Categoria central e categorias de $1^{\mathrm{a}}$ e $2^{\mathrm{a}}$ ordem relativamente ao futuro

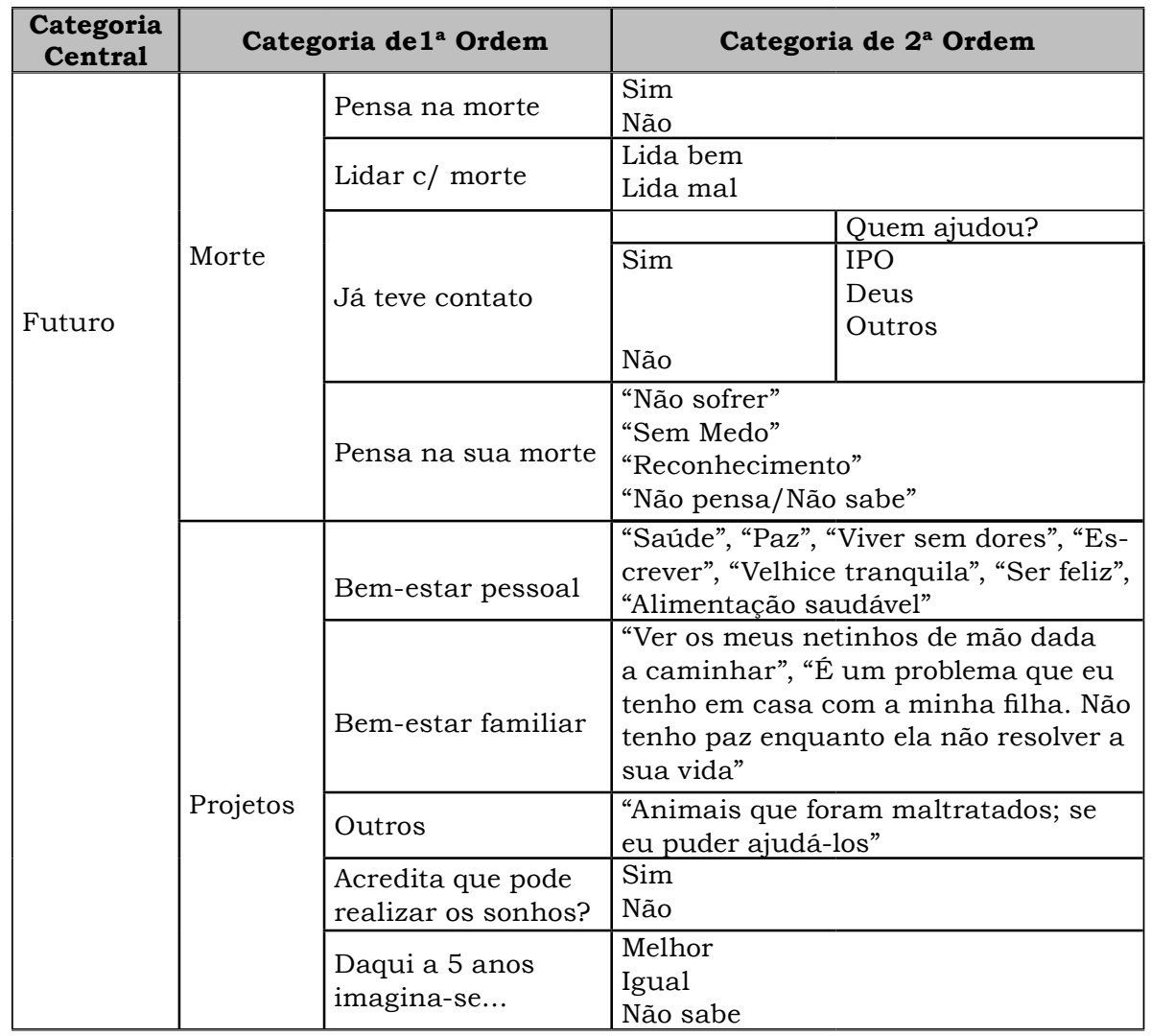

FONTE: elaboração própria

Os sonhos estão relacionados a maioria das vezes, com o bem-estar pessoal, e familiar. Sendo uma constante da vida, o sonho está presente também no doente oncológico, como uma estratégia de coping essencial para lidar com a doença: "ter saúde e paz", "o que tiver de acontecer me aconteça a mim, não aos outros", "saúde acima de tudo, depois que tive esta doença é rir muito, estar de bem comigo e com os outros", "viver o dia- a- dia com dinheiro 
suficiente. Gostava de ter netos e puder criá-los". "olhe é ver os meus netinhos de mãozinha dada a caminhar", "puder tirar a carta", "é todos os dias levantar-me e puder ir trabalhar". A maioria das utentes $(n=7)$ refere como projetos para o futuro questões relacionadas com o bem-estar pessoal "ter uma velhice tranquila", "escrever, mudar a minha casa", "acima de tudo primeiro a saúde", "viver todos os dias com alguma saúde e poucas dores físicas" ou familiar "ser feliz e fazer feliz os outros", "ter saúde para ver os meus netos crescerem-se ou formarem-se". Apenas uma utente diz "não faço projetos agora". Perante situações limite, como o surgimento de uma doença oncológica, os estudos evidenciam a procura de um sentido para a vida, e isso pode funcionar como uma possivel fonte positiva de adaptação à doença (10). A capacidade de continuar a encontrar um significado e sentido para a vida, mantendo projetos e sonhos para o futuro foi no nosso entender o mais interessante nas respostas a esta temática. Na nossa amostra foi possivel constatar que três utentes $(n=3)$ dizem que não pensam na morte. "Eu não penso, Porque não vale a pena pensar, a morte está aî", "eu não penso, eu nunca pensei na morte”, “não, não. Eu aqui posso morrer, mas o resto não“. As restantes utentes $(n=5)$ referem pensar na morte e uma refere mesmo pensar em suicídio: "Acho que sim, mas não é uma coisa que me assuste", "por muito que não queira a gente tem que pensar", "eu penso na morte, penso muito em suicídio, penso muito nisso", "devemos pensar, todos caminhamos para lá", "penso na morte, diariamente". O tema pensar na morte continua a ser tabu na nossa cultura, a distância existente na nossa relação com a nossa própria vida, e a dificuldade de comunicação connosco, tão bem evidenciadas nas respostas das utentes que nunca pensaram na morte. A doença, sobretudo quando a morte é uma possibilidade, agudiza a consciência de que a vida é preciosa e de quão preciosa é uma determinada vida (10). Apesar de algumas das utentes referirem pensar na morte, a dificuldade em aceitar e enfrentar a morte parecem evidentes na nossa cultura (10). Ainda em relação ao futuro, três utentes $(n=3)$ consideram que daqui a cinco anos vão estar melhores: "Mais feliz, mais alegre", "talvez a passear, viajar", "estar com o meu companheiro, que Deus mo guarde e juntos, gozarmos a vida". Outras três utentes $(n=3)$ referem não saber: "Cinco anos, é pensar muito, a gente vai gradualmente, devagarinho.", "não sei, só Deus sabe", "não, imagino, não sei se vou cá estar”. Enquanto as restantes duas utentes (n=2) dizem que vão estar iguais. "estou a ver-me como agora", "Igual, igual, igual". É muito interessante a análise desta questão, pois verificamos que apesar da adversidade e das mulheres com cancro da mama estarem afetadas em inúmeras dimensões, biológica, social e psicológica há uma capacidade para a procura de bem-estar. Esta experiência poderia contribuir para gerar emoções positivas e predispor a sentir que a vida tem significado. Isto fica evidente nas respostas a esta pergunta, ao acreditarem que podem estar iguais ou melhor, estas mulheres estão já a reapreciar a vida, reorganizando prioridades e a ter um crescimento positivo (30). A literatura refere que há uma evolução gradual no sobrevivente de cancro, que aumenta a confiança na vida, e que enquanto alguns sobreviventes desfrutam da ideia de cura, outros vivem a vida sob o lema "um dia de cada vez" (23). É muito interessante 
verificar que apesar das respostas dadas, a totalidade das utentes $(n=8)$ acredita que pode realizar os sonhos: "Ai acredito. Ai acredito", "tenho fé e esperança", "ai isso, acredito", "acredito, no fundo só estou a sonhar", "alguns, o meu maior sonho é ver o meu filho evoluir", "sim, acredito nem que seja em sonho". A necessidade de manter projetos para o futuro e não abdicar dos sonhos, mesmo quando reconhecem ser sonhos "pequenos" parece-nos ser uma tentativa de motivação para manter o sentido da vida, sendo sobretudo nos momentos em que as pessoas atravessavam percursos de doença ou outros momentos de sofrimento nas suas vidas que esta questão do sentido de vida emerge (21). Encontramos a procura de um sentido na vida nas mulheres que entrevistamos, pois em cada uma delas havia um sonho para realizar, mesmo que esse sonho fosse ver os netos crescer, o filho evoluir, tirar a carta, ou apenas puder ir trabalhar todos os dias. A maioria das utentes $(n=7)$ refere já ter tido contacto com a morte, quer através da sua própria experiência com o cancro, quer através da morte de alguém: "Sim, já tive. Esta última cirurgia foi muito dolorosa. Passei muito mal mesmo, muito mal", "já, era cama sofá, sofá cama, estava mesmo doente", "quando tive o diagnóstico de cancro, como me tinha morrido a minha irmã há dois anos, eu pensei que ia morrer", "contacto com a morte que tive, foi o meu marido", "já tive a minha falecida mãe". Apenas uma utente refere nunca ter tido contacto com a morte. Alguns estudos salientam que é possivel, proporcionar melhor qualidade de vida no processo de morrer e morte mais serena e digna, através de intervenções psicoterapêuticas que associam relaxamento mental, imagens mentais e espiritualidade (28). Cinco utentes $(n=5)$ referem lidar mal com a morte de alguém; "Ainda é muito complicado, acho que nunca estou preparada", "e muito mau, não foi experiência que gostasse de ver", "vou à capela, mas é difícil, agora já me custa muito ir", "e complicado e ao mesmo tempo sinto-me impotente", "afinal a morte causa-me pânico". Apenas três utentes $(n=3)$ referem lidar bem com a questão da morte de alguém: "Pela $1^{\mathrm{a}}$ vez beijei uma pessoa morta e não me custou", "procuro não interiorizar muito", "da minha mãe eu não lidei mal, que a minha mãe sofreu muito, ela partiu e fiquei aliviada". Três das utentes $(n=3)$ referem ter sido ajudadas a lidar com a ideia de morte pela equipa médica do hospital. Outras três utentes dão respostas ligadas a espiritualidade para lidar com a ideia de morte: "Monga budista, fui a uma palestra dela e fez-me muito bem a maneira como eles vêm a morte", "simplesmente faço as minhas orações", "a minha formação bíblica e moral que eu tive conhecimento e estudei durante tantos anos". Uma outra utente refere não ter tido "Ninguém" para lidar com a ideia de morte enquanto outra refere: "Amigas mais novas, umas já faleceram, outras ainda cá estão”. Não é fácil para o profissional de saúde intervir nas situações de morte. A maioria das unidades de saúde é mais voltada para o tratar do que para o cuidar do processo de morrer (21). Muitas destas mulheres, evidenciam nas suas respostas a procura pela dimensão espiritual perante a morte, demonstrando que a espiritualidade pode ser uma dimensão importante do homem, a par da dimensão biológica, intelectual, emocional e social, constituindo aquilo que o diferencia na sua singularidade e pessoalidade. Isso fica evidente em várias respostas, quer na procura de uma 
palestra budista para encontrar explicações para a morte, quer na que faz orações para se sentir melhor, e ainda, na que refere ter estudado durante vários anos estes temas na sua formação bíblica e moral. Verificamos como o estar perante uma doença grave confronta o ser humano com a sua própria morte e o leva a procurar encontrar estratégias de coping, normalmente de cariz religioso para melhor lidarem com a doença. Diversos estudos indicam que algumas crenças e atitudes de cariz espiritual e religioso são utilizadas como estratégias de coping religioso para lidar com as perdas em situação de doença (23). Também podemos verificar da análise destes dados que a esperança no futuro constitui uma importante estratégia de coping, auxiliando a pessoa a lidar não apenas com a dor do momento que vive, mas também com a incerteza relativamente ao futuro (15). Esta esperança está patente na maioria das utentes entrevistadas, que apesar de todo o processo doloroso porque passaram continuam a acreditar e a ter esperança num futuro melhor e com mais saúde.

\section{Conclusão}

A presente investigação tentou identificar os conteúdos do discurso sobre a doença produzidos em mulheres doentes oncológicas e analisar de que forma este discurso se articula com a perceção da morte, perdão e os projetos futuros. Os resultados sugerem a existência de estratégias de coping, como o perdão, o desenvolvimento da espiritualidade e ainda a esperança no futuro, para lidar com situações de grande desespero e dor. Neste sentido, na nossa amostra foi possivel identificar uma enorme capacidade de mudança perante em situações de impotência e sofrimento, sugerindo a ideia de que quando já não somos capazes de modificar uma situação, como um cancro, somos desafiados a mudar-nos a nós mesmos. Consideramos que esta investigação abre as portas a novas investigações na compreensão do ser humano e dos significados mais intimos que nele habitam quando em situações limite de dor e sofrimento. Nem sempre o doente oncológico consegue expressar através das palavras, os pensamentos, sentimentos e medos, que o impacto da doença provoca nas suas vidas. Apesar dos avanços nos meios de diagnósticos e no tratamento do cancro, que muitos estudos indicam, a doença e o seu tratamento são uma fonte geradora de sofrimento para todos os intervenientes, pacientes e familiares. Compete assim às equipas de saúde, que deverão ser multidisciplinares, um papel fundamental na arte de proporcionar um melhor acompanhamento ao nível do cuidar e acolher o paciente oncológico, dando espaço para ouvir os significados atribuídos após um diagnóstico de cancro, claramente associado a sofrimento e medo

\section{Conflicto de interés}

Los autores declaran no tener conflictos de interés.

\section{Financiación}




\section{Referências}

1. Melo L. Comunicação com o doente. Certezas e incógnitas. Loures: Lusociência-Edições Técnicas e Científicas Ld ${ }^{\mathrm{a}} ; 2005$.

2. Domingues V, Albuquerque E. Cancro do pulmão: Aspectos psicológicos e psiquiátricos. Rev Port Pneumol. 2008; 14: 261-289.

3. Barros H, Lunet N. Cancro: Uma Perspectiva de Saúde Pública. Arquivo de Medicina. 2006; 20: 31-36.

4. Sarna L, Brown J K Cooley, M E Willians, R D Chornecky, C, Padilla $\mathrm{G}$, et al. Quality of Life and Meaning of Illness of Women With Lung Cancer. Oncol Nurs Forum. 2005; 32: 9-19.

5. Andreu Y, Galdón M J, Durá E, Martínez P, Pérez S, Murgui S. A longitudinal study of psychosocial distress in breast cancer: Prevalence and risk factors. Psychol Health. 2012; 27(1), 72-87.

6. Banthia R, Malcarne VL, Ko CM, Varni JW, Sadler G R. Fatigued breast cancer survivors: The role of sleep quality, depressed mood, stage and age. Psychol Health. 2009; 24(8), 965-980.

7. Hebert R, Zdaniuk B, Schulz R, Scheier M. Positive and negative religious coping and well-being in women with breast cancer. J Palliat Med. 2009; 12(6), 537-545.

8. Schmid-Büchi S, den Borne B, Dassen T, \& Halfens R J. Factors associated with psychosocial needs of close relatives of women under treatment for breast cancer. J Clin Nurs. 2011; 20(7-8), 1115-1124

9. 9. Jones J M, Cheng T, Jackman M, Rodin G, Walton T, \& Catton P. Self-efficacy, perceived preparedness, and psychological distress in women completing primary treatment for breast cancer. Journal of Psychosocial Oncology. 2011; 28(3), 269-290.

10. Friedman L C, Barber C R, Chang J, Tham Y L, Kalidas M, Rimawi M F, \& Elledge R. Self-blame, self-forgiveness, and spirituality in breast cancer survivors in a public sector setting. J Cancer Educ. 2010; 25(3), 343-348.

11. Romero C, Friedman L C, Kalidas M, Elledge R, Chang J, \& Liscum K R. Self-forgiveness, spirituality, and psychological adjustment in women with breast cancer. J Behav Med. 2006; 29, 29-36.

12. Strauss A, Corbin J. Pesquisa qualitativa. Técnicas e procedimentos para o desenvolvimento da teoria fundamentada ( $2^{\mathrm{a}}$ ed.) Porto Alegre: Artmed; 2008.

13. Streubert HJ, Carpenter DR. Investigação qualitativa em enfermagem: avançando o imperativo humanista. trad. Ana Paula Sousa Santos. ( $2^{\mathrm{a}}$ ed.) Loures: Lusociência, 2002. XXI, p. 383.

14. Fernandes E, Maia A. Grounded Theory. En: Fernandes, L. Almeida, compiladores. Métodos e técnicas de avaliação: contributos para a prática e investigação psicológica. Braga. CEEP-UM; 2001. p 49-76.

15. Enright R, Fitzgibbons R. Helping clients forgive: No empirical guide for resolving anger and restoring hope. Washington, DC: American Psychological Association; 2000. 
16. 16. Hansen MJ, Enright RD, Baskin TW, Klatt J. A palliative care intervention in forgiveness therapy for elderly terminally-ill cancer patiens. J Palliat Care. 2009; 4: 5-30.

17. Zechmeister J, Romero C. Victim and offender accounts of interpersonal conflict: Autobiographical narratives of forgiveness and unforgiveness.J Pers Soc Psychol. 2002; 82: 675-686.

18. Begovic-Juhant A, Chmielewski A, Iwuagwu S, \& Chapman L A. Impact of body image on depression and quality of life among women with breast cancer. Journal of Psychosocial Oncology. 2012; 30(4), 446-460.

19. Ferrell B, Coyle N. The Nature of Suffering and. The Goals of Nursing. Oncol Nurs Forum. 2002; 35: 241-247.

20. Mcintyre T. Perda e sofrimento na doença: Contributo da psicologia da saúde. Psychologica. 2004; 35: 167-179.

21. Grimsbø GH, Ruland CM, Finset A. Cancer patients' expressions of emotional cues and concerns and oncology nurses' responses, in an online patient-nurse communication service. Patient Educ Couns. 2012; 88(1), 36-43.

22. 22. Aureliano WA. Corpo saúde e trabalho: (re) pensando os usos do corpo em "papéis femininos" na experiência de câncer da mama. Prática \& Trabalho. 2007; 26: 105-123.

23. Kállav E. Investigation of the relationship between religious growth, positive affect, and meaning in life in a sample of female cancer patients. Cogn Brain Behav. 2008; 12: 161-182.

24. Schlegel R J, Manning M A, Molix L A, Talley A E, \& Bettencourt B A. Predictors of depressive symptoms among breast cancer patients during the first year post diagnosis. Psychol Health. 2012; 27(3), 277-293.

25. Patrão I. Bem me quer, mal me quer... Bem nos quer, mal nos quer: A sexualidade, (in) fertilidade e o cancro. Análise Psicológica. 2005; 23: 289-294.

26. Erci B. Meaning in life for patients with cancer: validation of the Life Attitude Profile-Revised Scale. J Adv Nurs. 2008: 62: 704-711.

27. Brandão T, Schulz M S, \& Matos, P M. Psychological Intervention with couples coping with breast cancer: a systematic review. Psychol Health. 2014; 29(5), 491-516.

28. Salonen P, Kellokumpu-Lehtinen, PL, Tarkka M J, Koivisto A M, \& Kaunonen M (2011). Changes in quality of life in patients with breast cancer. J Clin Nurs. 2011; 20(1-2), 255-266.

29. Cardoso G, Luengo A, Trancas B, Vieira C, Reis D. Aspectos Psicológicos do Doente Oncológico. Revista do Serviço de Psiquiatria do Hospital Prof. Doutor Fernando Fonseca EPE. 2010; 6: 8-18.

30. Stanton A, Luecken L, MacKinnon D, Thompson E. Mechanisms in Psychosocial Interventions for Adults Living With Cancer: Opportunity for Integration of Theory, Research, and Practice. J Consult Clin Psychol. 2012; 8: 318-335. 